\title{
Retrospective histopathological classification of 1,108 skin biopsies from patients clinically suspected of having leprosy from Bahia, Northeast Brazil
}

\author{
Classificação histopatológica retrospectiva de 1.108 biópsias de \\ pele de pacientes com suspeita clínica de hanseníase \\ provenientes do Estado da Bahia, nordeste do Brasil \\ Aryon de Almeida Barbosa Júnior, Jamile Jambeiro, \\ Jonélia S.0. Cirqueira and Tânia Correa Silva
}

\begin{abstract}
We report a retrospective histopathological classification carried out under laboratory conditions by the method of Ridley \& Jopling of 1,108 skin biopsies from patients clinically suspected of having leprosy from Bahia, Northeast Brazil.
\end{abstract}

Key-words: Leprosy. Skin. Pathology.

Resumo Apresenta-se a classificação histopatológica retrospectiva, segundo Ridley e Jopling de 1.108 biópsias de pele de pacientes clinicamente suspeitos de hanseníase provenientes do Estado da Bahia, Brasil.

Palavras-chaves: Hanseníase. Pele. Patologia

Centro de Pesquisas Gonçalo Moniz da Fundação Oswaldo Cruz, Salvador, BA.

Address to: Dr. Aryon de Almeida Barbosa Jr. Centro de Pesquisas Gonçalo Moniz/ FIOCRUZ. R. Valdemar Falcão 121, Brotas, 40295-001 Salvador, BA, Brasil.

Tel: (071) 356-0788; Fax:(071) 356-4292

E-mail: aryon@cpqgm.fiocruz.br

Recebido para publicação em 12/09/97. 
Since Ridley \& Jopling10 have proposed an accurate classification of leprosy according to immunity, in five groups with strict criteria for definition, this system have become generally accepted worldwide and is recommended under laboratory conditions for experimented pathologists 7 . There is no data in the available literature about the distribution according this criteria, of the leprosy cases from Bahia State, Northeast Brazil.

Skin biopsies of the great majority of the leprosy cases from Bahia are sent to the Gonçalo Moniz Research Center (CPGM/FIOCRUZ) for histopathological diagnosis, where, in the last ten years period, the pathological reports has been made by many pathologists using mostly the Madrid classification (two polar groups and one intermediate). However, a great variation was observed in the interpretation of both the histopathological examination and pathological reports, with consequent poor clinicopathological correlation. Because this fact, it seems of value to review and reclassify according Ridley \& Jopling criteria, the pathological material of thousand one hundred eighth reporting patients diagnosed clinically as leprosy from Bahia State received at the CPGM/FIOCRUZ in the last ten year period. The results of this retrospective analysis are presented here.

\section{MATERIAL AND METHODS}

Between 1986-1995, material of skin biopsies obtained from 1,108 untreated patients clinically suspected of having leprosy, was received at the CPGM/FIOCRUZ from Public Health Units (Secretaria de Saúde do Estado da Bahia and Fundação Nacional de Saúde) of diverse cities of Bahia, including the capital Salvador. It was assumed throughout that the patients were not in reaction. All paraffin blocks from skin biopsies of those cases were retrieved from the Histopathology Laboratory archives. Biopsies were taken from macular, papular or nodular lesions. Only one biopsy of each patient was taken either in the form of an elliptical biopsy (792 times) or as a punch biopsy (389 times). The biopsies had been fixed in $10 \%$ formalin for two to 14 days, because most cases came from health units far away from the interior of Bahia State. Histological preparations, sectioned at $5 \mu \mathrm{m}$ were stained by $\mathrm{H} \& \mathrm{E}$ and Fite-Faraco for classification and demonstration of $M$. leprae. The search for bacilli in the skin biopsies was done in only one histologic section. Slides stained for acid-fast bacilli were read for a minimum of $5 \mathrm{~min}$. per section and bacilli noted as present or not, irrespective of their staining characteristics. They were semiquantitatively graded in: absent, slight, moderate and intense. The slides were examined by one of us (AABJr) and classified according Ridley \& Jopling scale without referral to the clinical data supplied with each biopsy. In indeterminate leprosy, classification was based on both clinical and histological findings. Clinical diagnosis was based on presence of ill defined hypopigmented skin lesions with localized sensory changes. The finding of a small epithelioid cell granuloma around skin structures, even in the absence of demonstrable acid-fast bacilli and/or the presence of Schwann cell proliferation of nerves in such lesions, was taken as confirming the diagnosis of indeterminate leprosy.

Clinical data. There were 658 males and 450 females from 5 to 97 years old, with a mean of $31 . \pm 19$ (SD) years. Because there was lack of information concerning the precise location and the duration of the skin lesions in many cases, these data were not summarized.

\section{RESULTS}

The results of the histopathological classification according Ridley \& Jopling is summarized in the Table 1. In 546 (49.3\%) cases in spite of the clinical suspicion, the histology was indistinguishable from that of chronic dermatitis. In the others $562(50.7 \%)$ cases the histopathological diagnosis of leprosy could be made. There were $484(43.7 \%)$ paucibacillary (PB) patients: $160(14.5 \%)$ indeterminate (I), 64 (5.7\%) tuberculoid (TT), 260 (23.5\%) borderline tuberculoid (BT); and 78 (7\%) multibacillary patients: $10(0.9 \%)$ borderline borderline (BB), 9 $(0.8 \%)$ borderline lepromatous $(\mathrm{BL})$ and 59 (5.3\%) lepromatous (LL).

Table 1 - Histopathological diagnosis of skin biopsies obtained from 1,108 patients clinically suspected of having leprosy received between 1986-1995 at the CPGM/FIOCRUZ from Bahia Public Health Units.

\begin{tabular}{lrc}
\hline Histopathological diagnostic & Number & Percent \\
\hline Lepromatous leprosy & 59 & 5.3 \\
Borderline lepromatous & 9 & 0.8 \\
Borderline borderline & 10 & 0.9 \\
Borderline tuberculoid & 260 & 23.5 \\
Tuberculoid leprosy & 64 & 5.7 \\
Indeterminate leprosy & 160 & 14.5 \\
Chronic dermatitis & 546 & 49.3 \\
\hline Total & 1,108 & 100.0 \\
\hline
\end{tabular}


No sane skin tissue were submitted for histological examination. A summary of the main pathological changes in all suspected cases of leprosy is shown in the Table 2. The most striking feature was the inflammation of neurovascular bundles and skin appendages. Macrophages

Table 2 - Histopathological changes observed in 1,108 skin biopsies from patients with suspected leprosy.

\begin{tabular}{lrc}
\hline & Cases & Percent \\
\hline Sites of inflammation & & \\
perivascular (in the SEZ) & 1,040 & 93.9 \\
skin appendages & 978 & 88.3 \\
perineural & 562 & 50.7 \\
Thinning and atrophy of the epidermis & 936 & 84.5 \\
Distortion of skin appendages & 724 & 65.3 \\
Nerve damage & 521 & 47.0 \\
\hline
\end{tabular}

and lymphocytes were the predominant celltypes. In the patients showing only a chronic dermatitis, there was always mild to strong perivascular and/or periadnexal accumulation of lymphocytes. Inflammation was more conspicuous around skin appendages in the majority of cases. In 50.7 percent of all cases perineural inflammation was present either in the deep dermis or in the vicinity of sweat glands, with deformation and disturbed arrangement of the nerves. Sometimes there was also fibrosis of perineurium. The epidermis was frequently atrophic $(85 \%)$ in the confirmed leprosy cases. In this cases, disorganization of the skin appendages was characterized by atrophy and partial destruction, seen approximately in 65 percent of all cases.

The distribution of acid-fast bacilli and granulomata in skin biopsies in the histopathologycally confirmed leprosy cases is shown in the Table 3 . In indeterminate leprosy sections, scanty bacilli were found in 69 of 160 biopsies. In TT leprosy an intense inflammatory reaction was found, composed of epithelioid cells, frequent giant cells and many lymphocytes around nerves and adnexa with no bacilli. In BT leprosy, few bacilli were found in or around nerves and were surrounded by histiocytic and mild lymphocytic infiltrates. Giant cells could be seen in some biopsies. In BB many little epithelioid cells were diffusely spread trough the granulomas, with also diffuse little number of lymphocytes. Many bacilli were always present. In $\mathrm{BL}$ and more conspicuously in LL large number of bacilli could be seen in macrophages often with foamy aspect, without evidence of marked tissue hipersensivity.

Table 3 - Acid-fast bacilli and presence of granuloma in skin according to leprosy classification in 562 histopathologically confirmed cases out of 1,108 patients.

\begin{tabular}{|c|c|c|c|c|c|c|}
\hline \multirow[t]{2}{*}{ Classification } & \multirow[b]{2}{*}{ Cases } & \multirow[b]{2}{*}{$\%$} & \multicolumn{2}{|c|}{$\begin{array}{l}\text { Histological type of } \\
\text { inflammatory infiltrate }\end{array}$} & \multicolumn{2}{|c|}{$\begin{array}{c}\text { Presence of acid-fast bacilli } \\
\text { using Fite-Faraco stain }\end{array}$} \\
\hline & & & lepromatous & tuberculoid & number & $\%$ \\
\hline Indeterminate & 160 & 28.5 & 0 & 0a & 69 & 43.1 \\
\hline Tuberculoid & 64 & 11.4 & 0 & 64 & 0 & 0 \\
\hline Borderline tuberculoid & 260 & 46.3 & 0 & 260 & 172 & 66.2 \\
\hline Borderline borderline & 10 & 1.8 & $3^{b}$ & $7 \mathrm{~b}$ & 10 & 100 \\
\hline Borderline lepromatous & 9 & 1.6 & 9 & 0 & 9 & 100 \\
\hline Lepromatous & 59 & 10.5 & 59 & 0 & 59 & 100 \\
\hline
\end{tabular}

a Lymphocityc infiltration around neurovascular bundles and adnexa.

b Overbalancing.

\section{DISCUSSION}

Leprosy is an outstanding example of a single disease that presents a spectrum of forms closely related to the cell-mediated immune response to the etiologic agent, which determines prognosis and constitutes the natural basis for the classification of this disease9. The extremes represented by patients hyperergic and anergic to $M$. leprae, with a continuous series of disease forms between the two poles. Ridley and Jopling standardized the nomenclature, generating a classification scale for leprosy, based in five groups strictly defined, being the most suitable system for research classification of the disease, intended for anybody who have full facilities for the investigation of patients 10 . This histological classification has been found to provide a workable and widely applicable system ${ }^{9}$ and is especially valuable in designing chemotherapeutic schedules, and for prognosis. Histological classification provides a convenient means of 
standardization between patients at widely distant centers. It has the advantage over clinical classification, which it supplements, that it gives a better indication of any recent shifts in a patient's position in the spectrum ${ }^{9}$. However, the performance of this classification scale is less favorable when employed by histopathologists who see leprosy cases infrequently than those experienced in this disease 3 , but even experienced pathologists sometimes pass through and report difficulties in the use of Ridley and Jopling classification 58 . It is still a matter of controversy if this classification should be modified. Some authors believe for classification purposes that the weight given to different signs and/or histopathological parameters for classifying leprosy cases (especially TT, BB and I) needs to be reassessed2. Others have even suggested that for uniformity of understanding and reporting, terminologies need to be narrowed down and restricted to only definite, suggestive, or no diagnosis of leprosy8. In fact, having satisfactory skin biopsies, the inherent difficulties in the histopathological diagnosis in leprosy stems, in part, from the unablity to recognize and/or to valuate adequately the histopathological changes present in the skin sections.

Since there is a good concordance in histology between and within lesions ${ }^{4}$, adequate biopsies taken from established lesions are representative of the position within the clinicopathological spectrum of each instance of disease. Thus, the case distribution of the histopatologically confirmed leprosy cases of this historical series presumptively delineates for this time period, the distribution according the Ridley and Jopling criteria, of the untreated leprosy cases from
Bahia State. Histopathological and clinical diagnoses of the classification of leprosy, using this criteria, coincided in approximately $51 \%$ of the cases. However, the overall concordance figure between the clinical and histopathological diagnoses for different types of leprosy could not be determinate because frequently there was lack of complete clinical information. The implications of the misinterpretation and variation in the diagnosis of leprosy in the context of public health and case-management are evident, since early and adequate treatment should prevent serious disabilities as well as break the transmission chain. The differences in the interpretation of cellular evidence of inflammation revealed the importance of the examination method and time in arriving at a diagnosis of leprosy, disclosing additionally the need for training and further studies. Searching for mycobacterial antigens ${ }^{1}$ and residual nerve elements 6 in AFB-negative sections using immunohistochemistry; increases the certainty level of the diagnosis.

There was a predominance of borderline and lepromatous forms in the early years of the observation period. Conversely, in the more recent years the indeterminate and tuberculoid forms were preponderant. This may indicate that occurred a shift in the epidemiology of the disease in this area with higher transmissibility or that the diagnosis occurred more precociously. Unfortunately, nowadays there is no active search for leprosy in Bahia State. Perhaps a more vigorous seek for leprosy could change even more the frequency distribution pattern of the different forms of the disease observable in

\section{REFERENCES}

this region.

1. Barbosa Jr AA, Silva TC, Patel BN, Santos MI, Wakamatsu A, Alves VA. Demonstration of mycobacterial antigens in skin biopsies fron suspected leprosy cases in the absence of bacilli. Pathology Research and Practice 190:782-785, 1994.

2. Bhatia AS, Katoch K, Narayanan RB, Ramu G, Mukherjee A, Lavania RK. Clinical and histopathological correlation in the classification of leprosy International Journal of Leprosy and Other Mycobacterial Diseases. 61:433-438, 1993.

3. Binford $\mathrm{CH}$, Meyers WM, Walsh GP. Leprosy. Jounal of the American Medical Association 247:2283-2292, 1982.
4. Cree IA, Srinivasan T, Krishnan SA, Gardiner CA, Mehta J, Fisher CA, Beck JS. Reproducibility of histology in leprosy lesions. International Journal of Leprosy and Other Mycobacterial Diseases 56:296301, 1988.

5. Fleury RN. Difficulties in the use of Ridley and Jopling classification: a morphological analysis. Hansenologia internationalis 14:101-106, 1989.

6. Fleury RN, Bacchi CE. S-100 protein and immunoperoxidase technique as an aid in the histopathologic diagnosis of leprosy. International Journal of Leprosy and Other Mycobacterial Diseases 55:338-344, 1987.

7. Neves RG, Hahn MD, Bechelli LM, Melchior Jr E, 
Pagnano PM, Haddad N. Comparative analysis between clinical diagnosis and histopathologic examinations carried out aocording to the criteria of the Madrid and Ridley-Jopling classifications. Hansenologia internationalis 7:8-14, 1982.

8. Porichha D, Misra AK, Dhariwal AC, Samal RC, Reddy BN. Ambiguities in leprosy histopathology. International Journal of Leprosy and Other
Mycobacterial Diseases 61:428-432, 1993.

9. Ridley DS. Histological classification and the immunological spectrum of leprosy. Bulletin of the World Health Organization 51:451-464, 1974.

10. Ridley DS, Jopling WH. Classification of Leprosy according to immunity. A five group system. International Journal of Leprosy 34:255-273, 1966. 